\title{
Case study of creativity in asynchronous online discussions
}

\author{
Timothy Corfman ${ }^{1}$ and Dennis Beck ${ }^{2^{*}}$
}

\author{
*Correspondence: dennis.beck@ \\ mail.waldenu.edu \\ ${ }^{2}$ Department of Curriculum and \\ Instruction, College of Education and \\ Health Professions, 216 Peabody Hall, \\ University of Arkansas, Fayetteville, AR \\ 72701, USA \\ Full list of author information is \\ available at the end of the article
}

\begin{abstract}
It is vital for online educators to know whether the strategies they use help students gain twenty-first-century skills like creativity. Unfortunately, very little research exists on this topic. Thus, the purpose of this study was to determine whether participation in online courses can help students develop creativity using asynchronous online discussions, textbooks, and teacher developed materials. A case-study approach was used and one professor, recognized by her peers for her expertise in online education, and three of her students were interviewed. Asynchronous online discussions (29) were also collected and analyzed using a sequential process of building an explanation, checking the explanation against the data, and repeating the process. Key results from the study indicated that project-based prompts, problem-based prompts, and heuristics used in asynchronous online discussions can help promote creativity. Future research should explore a more diverse group of participants and academic subject areas.
\end{abstract}

Keywords: Creativity, Asynchronous online discussions

Many colleges have increased the number of online classes that they offer; however, many university presidents and community members doubt the capability of online programs to prepare students to succeed professionally in the twenty-first century (Parker, Lenhart, \& Moore, 2011). Thus, it is important to determine whether online programs can equip students with the necessary skills to be successful professionally in the twenty-first century. One skill that government officials, corporate leaders and teachers have recognized as vital for student success is creativity (Colby \& Ortman, 2015). Unfortunately, little research has been done to ascertain the outcome online classes have on the creativity of students who take online classes. A common instructional strategy used in online classes is asynchronous discussion (Cho \& Tobias, 2016; Gao, Zhang, \& Franklin, 2013). Asynchronous discussion boards enable numerous students to participate and interact with each other regarding a specific topic. Asynchronous discussion boards are often a central component of the courses (Cho \& Tobias, 2016; Gao et al., 2013) along with teacher developed materials and textbooks. Unfortunately, there is little research on the use of asynchronous discussion boards to help students develop creativity. As a result, it is important to determine whether student use of asynchronous online discussions, textbooks, and teacher developed materials can help students to develop creativity. In this study, creativity, as conceptualized through Amabile, 1983, 1988; Amabile \& Pillemer, 2012) componential model of creativity, is examined.

(c) The Author(s). 2019, corrected publication 2021 Open Access This article is distributed under the terms of the Creative Commons Attribution 4.0 International License (http://creativecommons.org/licenses/by/4.0/), which permits unrestricted use, distribution, and reproduction in any medium, provided you give appropriate credit to the original author(s) and the source, provide a link to the Creative Commons license, and indicate if changes were made. 


\section{Review of the literature}

For an idea or product to be judged creative, it must be novel and capable of being used (Corazza, 2016; Kaufman, 2009). Per the componential model of creativity (Amabile, 1983, 1988; Amabile \& Pillemer, 2012), creativity arises from the interaction of three components within a person: (a) domain-relevant skills, (b) creativity-relevant processes, and (c) task motivation; and one component outside a person: the social environment in which the person is working. Domain-relevant skills are the factual knowledge and domain expertise that a creative individual possesses (Amabile, 1983, 1988; Amabile \& Pillemer, 2012). Creativity-relevant processes are the general cognitive skills that promote the generation of ideas (Amabile, 1983, 1988; Amabile \& Pillemer, 2012). Task motivation is the intrinsic motivation that the person has for completing the task (Amabile, 1983, 1988; Amabile \& Pillemer, 2012). Social environment refers to the environment in which the person is working (Amabile, 1983, 1988; Amabile \& Pillemer, 2012).

Several researchers have considered how teachers can enable students to be more creative. These researchers have discovered that helping students to be creative necessitates that teachers possess knowledge of what creativity is and what it looks like. Beghetto and Kaufman (2013) proposed that instructors who were required to teach creativity while lacking deep understanding of what creativity is might be doing more damage than good. They also suggested that teachers need to understand five essential principles before creativity is added to the curriculum. First, teachers must realize that creativity is not just novelty. Second, teachers must know that there are various levels of creativity. Third, teachers must appreciate that some environments inhibit creativity while others stimulate it. Fourth, teachers must know that creativity is not free. Finally, teachers must know that there is an appropriate time for creativity.

Teachers should model and provide opportunities for creativity. They can do this by first keeping creativity at the forefront when developing classroom environments (Starko, 2013). Modeling and reinforcement should play a primary role in making creativity a part of every lesson (Beghetto \& Kaufman, 2013). Additionally, students need to have their creativity triggered (Garner, 2013), so teachers should carefully select the motivational techniques that are used to urge students to be creative (Beghetto \& Kaufman, 2013), and always provide students opportunities to demonstrate their creativity (Beghetto \& Kaufman, 2013).

Teachers need to help students develop the mindsets required for creativity (Starko, 2013). Part of this is helping students gain content knowledge (Gregory, Hardiman, Yarmonlinskaya, Rinne, \& Limb, 2013). This should include how to visualize and how to get in the habit of noticing (Garner, 2013), as well as how to ponder the ramifications of their solutions (Gregory et al., 2013) while thinking in an interdisciplinary manner with creativity (Starko, 2013). Teachers also need to help students develop the skills required for creativity (Starko, 2013). This may involve:

- How to gather sensory data (Garner, 2013).

- How to ask open-ended questions (Gregory et al., 2013).

- How to find more than one solution to problems (Gregory et al., 2013).

- How to generate new ideas (Greenstein, 2012).

- How to solve problems in various ways (Greenstein, 2012).

- How to work with mediators (Gregory et al., 2013). 


\section{Asynchronous online discussions}

Researchers have also considered how asynchronous online discussions can best be planned for student success. Gao et al. (2013) uncovered four ways that online instructors organize asynchronous online discussions: (a) constrained environments, (b) visualized environments, (c) anchored environments, and (d) combined environments. In constrained environments, teachers give students sentence starters or frames. In visualized environments, teachers provide students with software that allows them to turn their discussions into concepts maps. In anchored environments, teachers give students texts to annotate and ask students to turn in their annotated texts for the discussion. In combined environments, teachers ask students to participate in two or more types of discussion.

De Noyelles, Mannheimer Zydney, and Baiyun Chen (2014) reviewed the literature on asynchronous online discussions. They discovered that asynchronous online discussions are improved when instructors modeled good social presence, required participation in the discussions, and graded the discussions. De Noyelles et al. also uncovered three types of prompts that improved asynchronous online discussions: (a) problem-based prompts, (b) project-based prompts, and (c) debate-based prompts. De Noyelles et al. also discovered six types of teacher responses to students' posts that improved discussions: Questioning student responses, playing devil's advocate, providing timely, modest instructor feedback, allowing students to facilitate discussions, providing structure or protocol prompts, and providing audio feedback.

Pena-Shaff and Altman (2015) noticed that students who posted frequently in discussions were more likely to benefit from the discussion. Also, students who replied to other students were more likely to gain from the discussion. Thus, Pena-Shaff and Altman suggested that online teachers insist that students post a certain number of times. Additionally, Pena-Shaff and Altman discovered that introducing thinking than other prompts are. However, insufficient research has been done to establish whether asynchronous online discussions can be used to improve creativity. In the following pages, we describe a case study (Yin, 2014) that focuses on answering the question of whether asynchronous, online discussions can be used to improve creativity.

\section{Research questions}

We asked two research questions. This is the first question that we asked: How do asynchronous online discussions reflect Amabile's componential model of creativity?

(a) How do instructor prompts reflect Amabile's componential model of creativity?

(b) How do student-to-instructor interaction reflect the different components of Amabile's componential model of creativity?

(c) How do student-to-student interaction reflect the different components of Amabile's componential model of creativity?

This is the second question that we asked: How do the materials used in asynchronous online courses promote creativity per Amabile's componential model of creativity? 


\section{Ethical approval}

This study was part of a dissertation completed at Walden University. Committee members included Dr. Dennis Beck and Dr. Jennifer Smolka. Approval for the study was obtained through Walden University's Institutional Review Board (IRB). The IRB number was 07-29-16-016834. All participants agreed to participant in this study and signed an agreement that was approved by Walden's IRB. Pseudonyms for all participants and the university are used through out the document to protect confidentiality. Neither researcher had a conflict of interest with any of the participants or participating university.

\section{Methods}

The case study method as described by Yin (2014) was adapted for this study. Participants for this study were purposefully chosen from two graduate courses at a midsized public university in the United States. One instructor and three students were selected to participate in the study. Pseudonyms have been used to protect the identity of participants. Two student participants were between 20 and 30 years old. One student participant was between 55 and 65 years old. Teresa was completing a Master of Science in Education and was enrolled in one of the two courses. Teresa had a job in marketing. Vanessa was completing a Doctor of Philosophy degree in Education and was enrolled in both courses. She had previously worked in the legal profession. Cindy was working on a Doctor of Education degree and was enrolled in both courses. She worked in fire safety developing educational materials for firefighters. Dr. Jones taught both classes. She was a respected member of an educational technology professional association and had received several awards for creativity in her teaching. She had also taught both courses previously.

\section{Setting}

ITEC 3520 was taught online using the learning management system (LMS) Canvas in the spring of 2016. The purpose of this course was to familiarize students with the theoretical frameworks necessary to critically evaluate and create visual depictions of information. The course continued for 15 weeks and included the following topics: (a) visual literacy, (b) learning theories, (c) instructional design, (d) instructional technology, and (e) information presentation. Students began each week by watching a video created by the Dr. Jones. Students would then read any texts that were assigned for the week and participate in weekly asynchronous online discussions.

ITEC 3550 was also taught online using Canvas in the spring of 2016. The purpose of this course was to acquaint students with the practices, software, and applications used to create, operate, and develop multimedia presentations for educational purposes. The course continued for 15 weeks and included hands-on activities to help students practice and utilize multimedia design principles.

\section{Data collection and analysis}

Data was collected from several sources, including individual interviews with students enrolled in the courses, an interview with the instructor for the courses, transcripts of 
asynchronous online discussions from both courses, and other materials related to the courses.

All student interviews were conducted on Zoom (https://zoom.us/) following a student interview protocol (Creswell, 2007). The interviews were then transferred to a private YouTube channel that allowed the interviews to be transcribed using the closed captioning feature. After transcribing the interviews, we read the transcriptions while listening to the interviews to make sure that there were no errors. The questions in the interviews varied slightly from those on the student interview protocol because clarification about something that was said in a previous answer was sometimes needed.

Dr. Jones was interviewed on 3 January 2017. An instructor interview protocol was used. The interview was conducted using Zoom and then uploaded to a private YouTube channel. The close captioning feature of YouTube was used to transcribe the interview. After the interview was transcribed, we then listened to the interview while reading the transcriptions to ensure that errors were fixed. The transcription was then put into an Access database. Research questions and interview questions were aligned with the componential model of creativity.

Dr. Jones also shared copies of twenty-nine asynchronous online discussions from ITEC 3520 and ITEC 3550. The online discussions were entered into an Access database for easier coding during data analysis.

\section{Cleaning up the data stage 1}

A two-stage method of data analysis was used. The first stage was cleaning up the data and the second stage was finding patterns. First, the asynchronous online discussions were divided into prompts and threads. A prompt was the initial question or statement that was used to ignite the discussion. A thread was one student's response either to the prompt or another student's thread. The method for coding the interview was to give each new response by the person being interviewed an initial code and a comment code.

Second, the prompts and threads were given an initial code based on the componential model of creativity (Amabile, 1983, 1988; Amabile \& Pillemer, 2012): (a) domain-relevant skill, (b) creativity-relevant process, or (c) task motivation. Any discussion thread that concentrated mainly on aiding an individual in gaining knowledge of or expertise in the course's content was labeled a domain-relevant skill. Any discussion thread that focused mainly on helping a student learn a heuristic for creating something (Amabile, 1983, 1988; Amabile \& Pillemer, 2012), define a problem, gather information, organize information, combine concepts, generate ideas, evaluate ideas, implement a solution, or monitor a solution was labeled a creativity-relevant skill (Mumford, Medieros, \& Partlow, 2012). Finally, any discussion thread that concentrated mainly on praising, agreeing with, critiquing, or answering a student's post was labeled task motivation. The codes for task motivation were based on a study done by Karakaya and Demirkan (2015) that described environments that helped individuals be creativity in digital environments.

Next, domain-relevant skills were subcategorized by a code that showed the source of the domain knowledge. This type of subcategorization was done with domain-relevant skills to help answer RQ2. The three source codes used were (a) textbook, (b) real world, 
and (c) additional source. The initial codes for creativity relevant processes and task motivation were further categorized by type of comment. There were five comment codes for creativity-relevant processes: (a) heuristic, (b) openness, (c) suspending judgement, (d) broad categories, and (e) breaking patterns. Our rationale for the comment codes for the creativity-relevant processes were types of creativity-relevant processes described by Amabile (1983, 1988) and Amabile and Pillemer (2012). Also, there were four comment codes for task motivation: (a) praise, (b), critique, (c) answering, and (d) agreeing. Since the social environment plays an important role in task motivation (Amabile, 1988), these codes were based on a study of what enables students to be creative in digital environments done Karakaya and Demirkan (2015). Finally, all of the prompts and threads received a type of response code: (a) student feedback, (b) teacher feedback, and (c) original response.

The same coding process was used for prompts except the type of response was left blank in prompt coding because the information was redundant. See Table 1 for all the codes used in the study.

\section{Finding patterns stage 2}

Using Yin's (2014) explanation building process, four themes were uncovered: (a) heuristics, (b) openness/suspending judgement, (c) agreeing/praise, and (d) answering/critiquing. One theme that emerged was that the discussions helped students develop heuristics for solving problems. These heuristics might be general, or they might be specific to solving one problem or evaluating one solution to a problem. One specific heuristic that was given was brainstorming. One chapter in the course textbook was devoted to teaching students how to brainstorm. Another theme that emerged was openness/suspending judgement. Dr. Jones developed openness and the ability to suspend judgment by asking open-ended questions. The term that interviewees used for openness and suspending judgement was flexibility. Both agreeing and praising occurred frequently in the asynchronous online discussions. Students were quick to tell their peers that they had done an excellent job or that they concurred with an answer to a given prompt. Both students and Dr. Jones answered questions when asked. Dr. Jones would answer questions that were asked other students if she had knowledge that was not available to students in the class. Students were slow to give negative feedback on the work of their peers. Dr. Jones balanced her praise with providing negative feedback that

Table 1 Coding key

\begin{tabular}{|c|c|c|c|}
\hline Componential Model of Creativity & Initial Code & Comment Code & Type of Response \\
\hline Domain-relevant skill & $\mathrm{D}$ & $\begin{array}{l}\text { Textbook (TXT) } \\
\text { Real World (RW) } \\
\text { Additional Source (A) }\end{array}$ & $\begin{array}{l}\text { Student Feedback (S) } \\
\text { Teacher Feedback (T) } \\
\text { Original Post }(\mathrm{O})\end{array}$ \\
\hline Creativity-relevant process & C & $\begin{array}{l}\text { Heuristic }(\mathrm{H}) \\
\text { Openness }(\mathrm{O}) \\
\text { Suspending Judgement }(\mathrm{J}) \\
\text { Broad Categories (BC) } \\
\text { Breaking Patterns (BP) }\end{array}$ & $\begin{array}{l}\text { Student Feedback (S) } \\
\text { Teacher Feedback }(\mathrm{T}) \\
\text { Original Post }(\mathrm{O}\end{array}$ \\
\hline Task Motivation & $\mathrm{T}$ & $\begin{array}{l}\text { Praise }(P) \\
\text { Critique }(C) \\
\text { Answering }(A n) \\
\text { Agree }(A g)\end{array}$ & $\begin{array}{l}\text { Student Feedback (S) } \\
\text { Teacher Feedback }(\mathrm{T}) \\
\text { Original Post }(\mathrm{O}\end{array}$ \\
\hline
\end{tabular}


was designed to help students improve their final projects. See Table 2 for how frequently comments related to each component of Amabile's (1983, 1988, Amabile and Pillemer, 2012) model of creativity were made.

\section{Results}

The results of this study are presented in relation to the research questions used in the study. During data analysis, the data received codes using labels developed based on the componential model of creativity (Amabile, 1983, 1988; Amabile \& Pillemer, 2012). Based upon the explanations that began to emerge from the data, answers to the research questions appeared. The key findings from this question was that asynchronous online discussions can help students to become more creative by helping them gain domain-relevant skills and creativity-relevant processes.

Research Question 1a: How do instructor prompts reflect Amabile's componential model of creativity?

\section{Acting as the heuristic for developing a specific product}

Sometimes the prompts served to teach creativity-relevant processes by acting as the heuristic for developing a specific product. One instructor prompt that helped to develop a creativity-relevant process by serving as heuristic came from week 6 of ITEC 3550:

... Explain the context (class/training, audience description, etc.), type of graphic (refer to C\&M Table 4.1), and how you expect the image to be used. Remember the graphic you create does not need to be perfect or high quality. It does, however, need to adhere to copyright law and should be attached or embedded in your reply.

Providing students with heuristics, instead of systematic guidelines, was valued by students as this quote from the interview with Teresa demonstrates, “... I think that allowed us some flexibility and we were able to be a little more creative on how we formulated our responses."

\section{Teaching a heuristic that could be used on a variety of projects}

At other times, the prompts served to teach creativity-relevant processes by teaching a heuristic that could be used on many different projects. Two examples of this type of prompt are in Table 3.

Table 2 Component frequency

\begin{tabular}{ll}
\hline Component & Number of Comments \\
\hline Domain Relevant Skills & 491 \\
Creativity Relevant Skills & 129 \\
Task Motivation & 1844 \\
Domain Relevant Skills/ Task Motivation & 1 \\
Misc. & 28 \\
Total & 2492 \\
\hline
\end{tabular}


Table 3 Heuristic prompts

\begin{tabular}{|c|c|c|}
\hline Week & Course & Prompt \\
\hline 2 & $\begin{array}{l}\text { ITEC } \\
3520\end{array}$ & $\begin{array}{l}\text { Pick one of the following activities and discuss. } \\
\text { 1. Select a tool from } 24 \text { Essential Mind Mapping and Brainstorming Tools (http://mashable. } \\
\text { com/2013/09/25/mind-mapping-tools/) and investigate it further. } \\
\text { 2. What are the system requirements for the tool? Is it web based or is it a standalone application? } \\
\text { 3. Are there free and paid versions of the tool? } \\
\text { 4. What are the differences in subscription levels, if any? } \\
\text { 5. Would you be willing to pay for it if you had to? } \\
\text { 6. How would you use the tool? } \\
\text { 7. What kind of projects would the tool help you with? } \\
\text { 8. Which step of the brainstorming process (as described in textbook, p. 15) could benefit the } \\
\text { most from using the tool? } \\
\text { 9. Identify a tool to help you create a sketchnote on a concept from Chapter } 2 \text { of textbook } \\
\text { and share the finished product. How does your personal visual literacy influence sketchnotes? } \\
\text { Lastly, share a tip about how you brainstorm }\end{array}$ \\
\hline 3 & $\begin{array}{l}\text { ITEC } \\
3550\end{array}$ & $\begin{array}{l}\text { What do you like most and least about giving peer feedback? How about when you receive } \\
\text { feedback? Does your reaction change based upon who is giving the feedback or to whom } \\
\text { you are giving feedback? How have you move beyond superficial comments? }\end{array}$ \\
\hline
\end{tabular}

\section{Prompts to develop openness}

The prompts also served to help students develop the creativity-relevant process of openness as this quote from Vanessa shows:

I mean, and that's been true of many of my courses when you go out and you actually find real world examples or other academic texts even that are related to the topic and again going back to that discussion with your peers where your able to dissect information, you know, other people bring in. You're able to really get a much broader understanding that in some ways also a more in-depth understanding.

This quote from Vanessa also shows that the prompts helped students to develop openness:

I think the main thing I got from the discussions was all the different experiences from peers because they were all coming from different backgrounds, from different areas, and so there was a very diverse way of thinking, and so that was kind of interesting because they were able to really help me think of things that I probably never would have thought of with my own experiences.

\section{Prompts to develop domain-relevant skills}

The prompts also served to help students to develop domain-relevant skills. This was most frequently done by asking students to apply knowledge gleaned from the course textbook, from teacher-made-videos, or from another source. The prompt from week 1 of ITEC 3550 was intended to help students apply domain-relevant skills:

Select two tutorial videos (hint: search YouTube (http://www.youtube.com) that appeal to you. How many of the videos use the rule of thirds? How many of the designs use the golden proportion? Do you see examples of the Gestalt laws in use? How are the six principles of design used, if at all?

Thus, prompts in ITEC 3520 and ITEC 3550 served several purposes. First, Dr. Jones used them to teach a heuristic. Second, she used them as heuristics. Third, she used 
them to help student develop openness. Finally, she used them to help students apply domain-relevant processes

Research Question 1b: How does student-to-instructor interaction reflect the different components of Amabile's componential model of creativity?

\section{Gaining domain-relevant skills by correcting student misunderstandings}

The interactions between students and instructors helped students gain domain -relevant skills. Sometimes the interaction between students and instructor in the asynchronous online discussions helped students to gain domain-relevant skills by correcting student misunderstandings or providing more information as this interaction between Dr. Jones and Cindy in week 2 of ITEC 3520 demonstrates. Cindy wrote:

I looked at Popplet, but it is a MAC program, and I can't run that. I will look for a PC tool. "Dr. Jones responded, "Popplet is available to use in any browser on Mac or PC. It can also be downloaded as an iOS app. If you go to the website http://www. popplet.com (http://www.popplet.com) and click the "try it out" button, you can experiment and/or click the "sign up" button in the upper right corner. Signing up lets you save and share your popplets."

Another example of when Dr. Jones provided additional information occurred in this exchange between Dr. Jones and Jack in week 1 of ITEC 3520. Jack wrote:

I think one of the biggest controversies in college sports is the use of certain symbols that may be "offensive" to a particular group, especially Native American symbols such as the Seminole Indian (which the tribe wholly supports) and a school like the University of North Dakota.

Dr. Jones responded:

The mascot issue has long fascinated me, primarily related to my knowledge of the Seminole Tribe support. When UND was first discussing changes, of course FSU came up, and I was surprised at how many active and passive voices in the conversation did not know about the relationship.

\section{Gaining domain-relevant skills by answering student questions}

Sometimes the interaction between students and instructor increased domain-relevant skills by answering questions that students brought up during the discussion as this exchange between Vanessa and Dr. Jones during week 5 of ITEC 3520 shows. Vanessa wrote:

I was actually thinking the same thing ... It seems that many of the logos that we have looked at are trying to explicitly or implicitly tell the viewer something about the company, organization, or product through the visual aspect of the logo. I am wondering what that would be in these two cases, and really, in the case of a lot of the car company logos. You brought up a great point ... 
Dr. Jones responded, "There are three ellipses visible in the company's logo. Each ellipse represents the heart of the customer, the heart of the product and the heart of technological progress."

Another instance when Dr. Jones provided additional information can be seen in this exchange between Adam, Jan, and Dr. Jones during week 4 of ITEC 3550.

Adam wrote, "So, can we make a backup so long as we don't ever share it with someone else?"

Jan replied, "That's a good question, Adam. I would think so if it was still only one individual using the material but going from paper to digital makes me wonder."

\section{Dr. Jones responded:}

I would have to dig for it, but there was a ruling that says if you own the physical copy of media (movie, song, etc.), you are entitled to one digital copy. This means that you could legally use an application like Handbrake to "rip" your favorite Disney films and store these on a personal device. However, you cannot distribute that digital copy and if you ever lose or sell the physical copy, you must delete the digital copy. As for iTunes or other digital media sellers, system backups are usually excluded from consideration. In other words, if you use Time Capsule on a Mac or a service for PC, that backed up copy isn't accessible except in the instance to restore a system. That said, if you lose your digital purchase, you can re-download it from the purchasing company. Some make it easier than others, but you can usually get it back.

\section{Gaining domain-relevant skills through inclusion of subject matter expertise}

Sometimes the interaction between students and instructor increased domain-relevant skills because the teacher added information that was not contained in the textbook, teacher-made videos, or additional readings as this response by Dr. Jones in week 13 of ITEC 3550 shows, "The point about the company being larger, with locations in multiple states, upon looking at the website makes me wonder if this is a case where the local franchise is not provided with stock marketing materials." Teresa valued the domain-relevant skills that she gained from her interactions with Dr. Jones as this quote shows, "I learned a lot more than I thought I was going to learn. I think one of the things that caught me by surprise is designing a logo."

Vanessa also valued the additional knowledge she gained from her interactions with Dr. Jones as this quote shows:

Yeah, I mean a lot of times, she would pop in and give us sort of directed information based on the discussions that were going on or questions that she saw popping up, so it would be useful particularly if we were having trouble with technology or finding resources or what not. It would be useful in those cases.

\section{Increasing task motivation and social environment}

The interaction between students and instructor also served to increase task motivation. One way that the interaction between students and instructor increased task motivation was by giving quality feedback. The most common type of feedback 
given by Dr. Jones was praise. This quote from week 1 of ITEC 3520 is an example of the praise that Dr. Jones would give, "Think your first observation really illustrates the role of the album cover in conveying a deeper message about the band. Nice choice!"

This quote from week 4 of ITEC 3550 also is another example of the type of praise that Dr. Jones would give, "Great find on the Canada vs. US copyright resource!"

I've had a similar conversation with UK faculty over "crown copyright." "Fascinating stuff when you look at country/cultural guidelines!"

This quote from Vanessa shows that students appreciated this positive feedback that they received from Dr. Jones, "Oh, yeah, absolutely. Dr. Jones always has a really good attitude and it's really sort of a cheerleader, in sort of a way, you know, to help everybody stay encouraged and not get frustrated or what not and so."

Student-to-teacher interaction also helped to create a social environment that was conducive to creativity as this quote from Vanessa demonstrates, "Oh, yeah, absolutely. She's always has a really good attitude and is really very sort of a cheerleader, in sort of a way, you know, to help everybody stay encouraged and not get frustrated or what not and so."

The student-to-instructor interaction served four functions. First, it enabled Dr. Jones to correct student misunderstandings and provide additional information not found in the textbook or other course materials. Second, it served as way for her to answer questions that students had as result of the discussion. Third, it helped her to encourage students to keep working on the projects. Fourth, it allowed her to create a social environment conducive to creativity. Finally, it enabled her to increase task motivation by providing a quality critique.

Research Question 1c: How does student-to-student interaction reflect the different components of Amabile's componential model of creativity?

\section{Adding information from sources other than course materials}

Student-to-student interaction increased domain-relevant skills by adding information from additional sources other than the materials provided by the instructor as this quote from Teresa from week 1 of ITEC 3520 demonstrates:

I find it interesting that in addition to the University of CS logo, the poster includes the logos of all their competitors on the dates USC plays them. First of all, as a public relations and communications professional for University of CS, I can tell you that the University of CS signature is not readily available for use by others without permission. It leads me to wonder if these logos are used within legal guidelines. Also, if another entity is not a sponsor of the event or publication, we typically do not want to "share the stage" with other entities. I think this element of the poster is unusual.

Another example of student-to-student interaction increasing domain-relevant skills by adding information from additional sources can be seen in this exchange between Cindy and Rachel in week 2 of ITEC 3520. 
Cindy wrote:

I do think that visuals/images can tell more about an individual's understanding and perception than a list of words. Your example of a process flow chart would be great to see how members of a group are thinking and where misconceptions lie. I think that going through a process like this would definitely benefit all learning styles -- auditory by listening to someone talk, visual by seeing the information in a graphic organizer or in the form of images and kinesthetic by writing or drawing. I hope I've answered your question. Let me know if I missed it.

Rachel responded:

That is so true, that the visuals give us a direct link into the student's schema regarding content learning/learned. This study suggests a positive benefit to the approach.

\section{Increasing task motivation through positive feedback}

Student-to-student interaction also increased task motivation by providing positive feedback. Vanessa found student-to-student interaction to beneficial to her in helping her keep task motivation:

Yeah, I think that for the most part they were very positive. Any type of criticism I got generally was sort of very constructive and not overly negative, and yeah, I mean, that certainly anytime you get positive feedback or even constructive criticism that it encourages you to continue what you're doing and sort of take more risks and whatnot because you seem to be on the right track and the information you're getting is useful.

\section{Research Question 2.}

How do the materials used in asynchronous online courses promote creativity per Amabile's componential model of creativity?

\section{Textbooks}

The textbooks played a critical role in helping students to develop domain-relevant skills as these quotes from the interviews demonstrate. Teresa described the textbook this way:

... White Space Is Not Your Enemy was a lot of review for me because a lot of it is what I do on a daily basis, but I love that book because it really did a great job. It was very direct, you know, and explained things very well and very clearly.

Vanessa described the textbooks this way, "That textbook I remember quite a bit and was really useful."

Cindy described the textbook this way when describing what the asynchronous online discussions did for her, "I was better off using the text." 
Dr. Jones also believed that the textbooks were useful in helping students to develop domain-relevant knowledge although she thought the other materials that she brought in from journals and other sources were just as valuable or more valuable, and she also got some of the discussion prompts from the textbooks as this quote shows:

I don't like to rely on textbooks. I'd rather do selected readings cause I don't want to make a student buy a book; however, that book I'm in love with and it's like 15 bucks on Amazon ... I've never had a student complain about it. In fact, my course evaluations almost always mentioned how awesome the book is because it's easy to read. It's easy to follow. It's written from a very practical standpoint with references back to research and practices and historical approaches to design so that I like to keep it. Some of my discussion questions actually come from the book, from the end of the chapters and that's one of the other reasons that I as an instructor like it.

Additionally, the textbook also helped students develop creativity-relevant processes. One entire chapter of the textbook was devoted to learning how to brainstorm ideas. Thus, the textbook helped students to develop domain-relevant skills and creativity-relevant processes.

\section{Teacher-made videos}

Teacher-made videos also played a critical role in promoting creativity.

Teresa described the role that teacher-made videos played in her learning in course this way, "Dr. Jones was amazing at that. Really that's one of the things that I take away from this program. I really want to do that in my own classes to be able to give that same kind of structure in my classes."

Vanessa described the value that the teacher-made videos had in this way:

Yea, I mean, a lot of times, if I recall correctly, she would, you know sort of gives a heads up of what we were going to be doing in the class, what sort of things we might be producing for the class for that week, and she would usually say, like, here are the things that you might want to use or can use that you have access to, so that would be helpful and sort of formulating that initial idea of okay this is where I need to go look for things, or this is what I should be thinking about when I'm drafting what I'm going to do or what not.

Dr. Jones also believed that her teacher-made videos were crucial to development of creativity in her classes as this quote shows, "At the very least they provide a huge impact. That practice actually won an award from the Association for Education Communication and Technology as a distance education best practice."

The teacher made videos played a significant role in helping students. They served to sum up the previous week's material and introduce the up-coming material.

The analysis by Cindy about the use of the asynchronous online discussions differed from the information presented by Teresa, Vanessa, and Dr. Jones. Cindy found little value the asynchronous online discussions. This quote expresses her feelings about the discussions, “... with Dr. Jones, it got way too long and too many multiple comments 
going back and forth. It was like going on Facebook in a way you had a political blog going."

Teresa, however, saw this lack of specificity as adding flexibility to projects, "I think that allowed us some flexibility and we were able to be a little more creative on how we formulated our responses."

\section{Discussion and conclusions}

The prompts in the case-study courses reflected the components of Amabile's componential model of creativity (Amabile, 1983, 1988; Amabile \& Pillemer, 2012). Two types of prompts used in the case-study courses fell into what de Noyelles et al. (2014) described as problem-based prompts and project-based prompts. Problem-based prompts ask participants to apply their knowledge by generating a solution to a problem (de Noyelles et al., 2014) while project-based prompts ask participants to solve a problem by developing a project (de Noyelles et al., 2014).

In solving the problems presented in the problem-based prompts and in completing the projects in the project-based prompts, students applied domain-specific skills. Domain-relevant skills are factual knowledge and expertise (Amabile, 1983, 1988; Amabile \& Pillemer, 2012). Problem-based prompts demonstrate best practices in teaching online courses by acting as triggering events (Akyol \& Garrison, 2011) that spur participants to become cognitively involved in the class by applying domain-relevant skills learned from the textbook, teacher-created videos, or additional-teacher-provided sources to real world issues.

In solving the problems presented in the problem-based prompts and in completing the projects in the project-based prompts, participants applied creativity-relevant processes. Creativity-relevant processes are processes that help with the generation of ideas (Amabile, 1983, 1988; Amabile \& Pillemer, 2012). According to Amabile (Amabile, 1983, 1988; Amabile \& Pillemer, 2012), one type of creativity-relevant process is a heuristic. Creativity-relevant processes is reflected in the asynchronous online discussion in case-study courses when project-based prompts provide a heuristic for completing a specific assignment or help to teach an all-purpose heuristic for generating ideas such as brainstorming.

This case study also showed that the student-to-instructor interaction in asynchronous online discussions could promote domain-relevant skills, and encourage creativity-relevant processes, and increase task motivation. The student-to-instructor interaction in asynchronous online discussions can demonstrate best practices in teaching online courses by allowing students to integrate ideas (Akyol \& Garrison, 2011). The integration of ideas in the asynchronous online discussions in the case-study courses served to help students gain domain-relevant skills allowing students to add the teacher's perspectives to their schemata of the topics being presented in the textbook, teacher-created videos, or additional-teacher-provided sources. De Noyelles et al. (2014) stated that domain-relevant skills are developed when instructors question or challenge student solutions to problem-based prompts. Student-to-instructor interactions in the asynchronous online discussions in the case-study courses helped students to solve problems by allowing the instructor to question and challenge student solutions. Student-to-instructor interactions also helped students gain domain-relevant skills by allowing the instructor to answer questions. 
Student-to-instructor interactions can help students to develop creativity-relevant processes by encouraging students to adopt a cognitive style that is conducive to creativity. Per Amabile (1988) a cognitive style that is conducive to creativity has the following characteristics: (a) exploring new cognitive pathways, (b) keeping response options open for as long as possible, (c) suspending judgement, (e) using broad categories to store information, and ( $f$ ) and breaking out of performance patterns. In the student-to-instructor exchanges that took place in the case-study courses, the instructor encouraged students to explore new cognitive pathways, and to keep options open for as long as possible, and to suspend judgment.

Student-to-instructor interactions in asynchronous online discussions can also increase task motivation. Karakaya and Demirkan (2015) discovered that a high frequency of feedback from evaluators can increase task motivation. Student-to-instructor interactions in asynchronous online discussions give instructors many opportunities to provide feedback that encourages students to keep working on solutions to problems. Additionally, student-to-instructor interactions allow students to seek help. Kamdar and Mueller (2011) suggested that help seeking is an intermediate variable between intrinsic motivation and creativity. Student-to-instructor interactions allow students to seek help from their instructor and thus maintain task motivation. In addition to increasing task motivation, the student-to-instructor interactions in asynchronous online discussions can increase domain-relevant skills. The componential model of creativity (Amabile, 1983, 1988; Amabile \& Pillemer, 2012) presupposes a feedback loop that increases domain-relevant skills (Amabile, 1983). In the case study courses, Dr. Jones frequently answered questions that students asked or added additional information that was needed to help students understand the material in the textbook.

This case study showed that the student-to-student interaction in asynchronous online discussions could promote domain-relevant skills, and encourage creativity -relevant processes, and increase task motivation. The student-to-student interaction facilitated creativity in much the same that the student-to-instructor interaction facilitated creativity.

As with the student-to-instructor interaction in the asynchronous online discussions, the student-to-student interaction in asynchronous online discussions can demonstrate best practices in teaching online courses by allowing students to integrate ideas (Akyol \& Garrison, 2011). The mixing of concepts in the asynchronous online discussions in the case-study courses assisted students in gaining domain-relevant skills by allowing students to add other students' perspectives to their schemata of the topics being presented in the textbook, teacher-created videos, or additional-teacher-provided sources. As with the student-to-instructor interaction in the asynchronous online discussions in the case-study courses, the student-to-student interaction can help students to develop creativity-relevant processes by stimulating students to adopt a cognitive style that is conducive to creativity. Per Amabile (1988) a cognitive style that is favorable to creativity has the following characteristics: (a) exploring new cognitive pathways, (b) keeping response options open for as long as possible, (c) suspending judgement, (e) using broad categories to store information, and (f) eliminate breaking out of performance patterns. In the student-to-student exchanges that took place in the case-study courses, the students encouraged their peers to examine new cognitive pathways, and to keep possibilities open for as long as possible, and to suspend judgment. 
As with the student-to-instructor interaction in the asynchronous online discussions in the case-study courses, the student-to-student interactions in asynchronous online discussions can increase task motivation by providing the instructor an opportunity to give constructive feedback. Per Amabile (1983), constructive feedback gives positive recognition for creative work and encourages the recipient to consider ideas. Additionally, constructive feedback avoids making comments that imply that recipient is incompetent. Karakaya and Demirkan (2015) discovered that a high frequency of feedback in an asynchronous online discussion from evaluators leads to an increase task motivation. In the case study courses, student-to-student interactions in asynchronous online discussions allow students to give peers positive, frequent feedback that stimulated feedback recipients to keep working on solutions to problems that are presented in the course.

As with the student-to-instructor interaction in the asynchronous online discussions in the case-study courses, the student-to-student interactions in asynchronous online discussions can increase domain-relevant skills. The componential model of creativity (Amabile, 1983, 1988; Amabile \& Pillemer, 2012) presupposes a feedback loop that increases domain-relevant skills (Amabile, 1983). In the case study courses, students frequently answered questions that other students asked or added new information that was needed to help their peers understand the material in the textbook.

\section{Research Question 2.}

How do the materials used in asynchronous online courses promote creativity per Amabile's componential model of creativity?

Garrison, Cleveland-Innes, and Fung (2010); Shea and Bidjerano (2009); and Sheridan and Kelly, (2010) have noted that the decisions that teachers make in designing and selecting the materials for courses have profound impact on what students take away from the course.

The textbook in an asynchronous online course can play a vital role helping students to gain domain-relevant skills, to develop creativity-relevant processes, and to retain task motivation. The textbook in the case-study courses helped students to gain domain-relevant skills by serving as a resource for the basic information that students would need to begin discussing the prompt provided by the instructor. In the asynchronous online discussions in the case study courses, the instructor often took the discussion prompts from the end of chapters in the textbook that students were reading for the courses. These questions became problem-based prompts and project-based prompts that de Noyelles e al., (2014) said could assist students in becoming cognitively involved in discussions. The textbook in the case-study courses also helped students to develop heuristics by including a chapter on brainstorming. Finally, the textbook in the case-study courses helped students to retain task motivation by explaining why the topic being discussed was important.

Teacher-made videos can play a key role in promoting creativity in asynchronous online courses. Teacher-made videos that include audio feedback can increase teacher presence in asynchronous online courses (de Noyelles et al., 2014), and this increased teacher presence can help students to gain domain-relevant skills. Teacher-made videos 
can serve to promote a social environment conducive to creativity by providing the instructors with another avenue for giving feedback. Additionally, teacher-made videos enable instructors to answer questions that come up during asynchronous online discussions. Finally, teacher-made videos provide a venue for giving direct instruction on creativity-relevant processes, such as brainstorming and providing feedback.

Additional teacher resources can play a key role in promoting creativity. Additional -teacher-provided resources help students to gain domain-relevant skills by serving as a resource for the basic information that students need to begin discussing the prompt and creating solutions to the problems provided by an instructor in an asynchronous online discussion. Like the teacher-made videos, the additional-teacher-provided resources enable instructors to answer questions that came up during the asynchronous online discussions and by allowing the instructor to provide feedback on student work.

High school instructors who teach their courses online can use this information to help their students become more creative. They can do this by adding teacher-made videos and by making sure that the prompts that are used in discussions help students to become more creative.

Conclusions are based on the findings and limitations of this study. The recommendations include developing studies that occur closer to the completion of the course, adding more participants, conducting in person interviews, and examining courses in different domains.

Future research should be conducted in which the interviews either take place concurrently with the course or immediately after the course is completed. This would ensure that interviewees have not forgotten valuable information that might explain how creativity was being expressed during the course.

Since creativity is a social construct (Moran, 2010), additional research on the way that asynchronous online discussions enhance creativity needs to be done with more participants, especially minority students. This will help to ensure that views of minority students will be included. Also, it will help to make sure that all potential viewpoints about how creativity is expressed.

More research on the way that asynchronous online discussions enhance creativity needs to be done where participants are interviewed in person. Not all participants in this study were equally adept at using Zoom. In person interviews would ensure that technology is not an obstacle to the expression of relevant information.

Since domain-relevant skills are important in an environment conducive to creativity (Amabile, 1983, 1988; Amabile \& Pillemer, 2012), further research on the way that asynchronous online discussions enhance creativity in courses in multiple domains needs to be undertaken. Asynchronous online discussions in online science courses, math courses, and English courses may display creativity differently than the courses examined in this study did.

\section{Limitations}

Limitations of this study came from the research design of the study and real-world limitations of the setting and demographics of the study. Limitations included data that was filtered through the lens of the interviewee, not all interviewees were able to express themselves equally, interviews were conducted via video conferencing, the number and type of participants was limited, and only one type of course was examined. 
Interviews provided information that was filtered through the lens of the interviewee (Merriam, 1998). The asynchronous online courses for this case study took place about six to nine months before the time that the participants were interviewed. Sometimes the participants had difficulty remembering what took place during the courses. The lack of remembering what happened during the course might have affected the accuracy of the answers that interviewees provided.

Not all interviewees were equally articulate (Merriam, 1998). Some participants could elaborate on the topics being asked about in the interview protocol while others had difficulty elaborating on the discussion prompts. Less articulate students needed encouragement and prompting. This encouragement and prompting may have biased their responses. While encouraging and prompting was a limitation, it was necessary to help some interviewees develop responses that were more than one or two words long. As result, the views of more articulate interviewees may have been weighted more than the views of less articulate interviewees skewing the results.

The interviews were conducted using Zoom. While Zoom allowed for both video and audio, it was different from having both the interviewer and the interviewee in the same location. While using Zoom was a limitation in this study, its use was justified because the interviewer and interviewees were over 1000 miles apart and the expense of travel would have been excessive. Additionally, not all interviewees were equally adept at using Zoom. Thus, the views of those who were adept with Zoom may have been given greater weight than those who were less adept with Zoom skewing the data.

The number of participants was limited. The small number of participants was justified because as Patton (2002) stated that there is no fixed number of participants needed for a case study only and multiple requests were made to get more student participants. While number of students was small, it was large enough to obtain rich information.

There was only one minority student in the case-study classes. While not ideal, this was justified because a case study examines a real-world event. In the case-study classes, only one minority student was enrolled, and he was unwilling to be interviewed. Minority students might view the activities that took place during the class differently than the White students in the courses did.

The courses in this study were both courses related to creating media for instructional purposes. Creativity might have been displayed differently if the courses studied had been science, math, or English.

\section{Acknowledgements}

This study was done for a dissertation at Walden University. Committee members were Dr. Dennis Beck and Dr. Jennifer Smolka. IRB approval was obtained from Walden University's University Review Board. The IRB approval number was 07-29-16-016834. 


\section{Authors' contributions}

TC was the primary researcher. He conducted the interviews, coded the documents, and wrote the initial drafts. DB was the chair of TC dissertation committee. As such, DB guided TC by helping TC find a place to conduct the case study, guiding TC in conducting the interviews, and guided TC in coding the material. DB also helped draft the article by providing guidance as to what should be added and cut to make the research fit an article format. Both authors read and approved the final manuscript.

\section{Competing interests}

Not applicable.

\section{Publisher's Note}

Springer Nature remains neutral with regard to jurisdictional claims in published maps and institutional affiliations.

\section{Author details}

${ }^{1}$ Highland High School, 39055 25th Street West, Palmdale, CA 93561, USA. 'Department of Curriculum and Instruction, College of Education and Health Professions, 216 Peabody Hall, University of Arkansas, Fayetteville, AR 72701, USA.

Received: 2 January 2019 Accepted: 2 May 2019

Published online: 12 June 2019

\section{References}

Akyol, Z., \& Garrison, D. R. (2011). Understanding cognitive presence in an online and blended community of inquiry: Assessing outcomes and processes for deep approaches to learning. British Journal of Educational Technology, 42(2), 233250. https://doi.org/10.1111/j.1467-8535.2009.01029.x.

Amabile, T. (1988). A model of creativity and innovation in organizations. Research in Organizational Behavior, 10(1), 123-167 Retrieved from http://web.mit.edu/curhan/www/docs/Articles/15341_Readings/Group_Performance/Amabile_A_Model_ of CreativityOrg.Beh v10 pp123-167.pdf.

Amabile, T., \& Pillemer, J. (2012). Perspectives on the social psychology of creativity. The Journal of Creative Behavior, 46(1), 315. https://doi.org/10.1002/jocb.001.

Amabile, T. M. (1983). The social psychology of creativity: A componential conceptualization. Journal of Personality and Social Psychology, 45(2), 357-376. https://doi.org/10.1037/0022-3514.45.2.357.

Beghetto, R., \& Kaufman, J. (2013). Fundamentals of creativity. Educational leadership, 70(5), 10-15 Retrieved from http://web.b. ebscohost.com.ezp.waldenulibrary.org/ehost/pdfviewer/pdfviewer?vid=1\&sid=3789f4ef-6e1f-4070-80a2fcc7a651f54b\%40sessionmgr103.

Cho, M., \& Tobias, S. (2016). Should instructors require discussion in online courses? Effects of online discussion on Community of Inquiry, learner time, satisfaction, and achievement. The International Review of Research in Open and Distributed Learning, 17(2), 123-140. https://doi.org/10.19173/irrodl v 17i2.2342.

Colby, S., \& Ortman, J. (2015). Projections of the size and composition of the U.S. population: 2014 to 2060. US Census Bureau. Retrieved from https://www.census.gov/content/dam/Census/library/publications/2015/demo/p25-1143.pdf.

Corazza, G. (2016). Potential originality and effectiveness: The dynamic definition of creativity. Creativity Research Journal, 28(3), 258-267. https://doi.org/10.1080/10400419.2016.1195627.

Creswell, J. (2007). Qualitative inquiry \& research design: Choosing among five approaches, (2nd ed., ). Thousand Oaks: Sage Publications, Inc.

de Noyelles, A. A., Mannheimer Zydney, J., \& Baiyun Chen, B. (2014). Strategies for creating a Community of Inquiry through online asynchronous discussions. Journal Of Online Learning \& Teaching, 10(1), 153-165 Retrieved from http://jolt.merlot. org/vol10no1/denoyelles_0314.pdf.

Gao, F., Zhang, T., \& Franklin, T. (2013). Designing asynchronous online discussions environments: Recent progress and possible future directions. British Journal of Educational Technology, 44(3), 469-483. ERIC Number: EJ1006692.

Garrison, Cleveland-Innes, and Fung (2010). Exploring causal relationships among teaching, cognitive and social presence: Student perceptions of the community of inquiry framework. The Internet in Higher Education, 13 (1-2), 31-36. https://doi.org/10.1016/.j.heduc.2009.10.002.

Garner, B. (2013). The power of noticing. Educational Leadership, 70(5), 48-32. Retrieved from http://sfxhosted.exlibrisgroup. $\mathrm{com} /$ waldenu?sid=google\&auinit=RA\&aulast=Beghetto\&atitle=Fundamentals+of + Creativity.\&title=Educational + Leadership\&volume $=70 \&$ issue $=5 \&$ date $=2013 \&$ spage $=10 \& i s s n=0013-1784$

Greenstein, L. (2012). Assessing 21st-century skill21st-century skills: A guide to evaluating mastery and authentic learning. Thousand Oaks: Corwin A Sage Company.

Gregory, E., Hardiman, M., Yarmonlinskaya, J., Rinne, L., \& Limb, C. (2013). Building 134 creative thinking in the classroom: From research to practice. International Journal of Educational Research, 62, 43-50. https://doi.org/10. 1016/j.ijer.2013.06.006

Karakaya, A., \& Demirkan, H. (2015). Collaborative digital environments to enhance the creativity of designers. Computers in Human Behavior, 42, 176-186. https://doi.org/10.1016/j.chb.2014.03.029.

Kaufman, J. (2009). Creativity 101. New York: Springer Publishing Company.

Merriam, S. (1998). Qualitative research and case study in education: Revised and expanded from case study research in education. San Francisco: Jossey-Bass Publishers.

Moran, S. (2010). The roles of creativity in society. In J. C. Kaufman, \& R. J. Sternberg (Eds.), The Cambridge handbook of creativity [kindle DX version], (pp. 73-89). New York: Cambridge University Press Retrieved from amazon.com.

Mumford, M., Medieros, K., \& Partlow, P. (2012). Creative thinking: Processes, strategies, and knowledge. Journal of Creative Behavior, 46(1), 20-47. https://doi.org/10.1002/jocb.003.

Parker, K., Lenhart, A., \& Moore, K. (2011). The digital revolution and higher education: College presidents, public Differ on value of online learning. ERIC Number: ED524306. 
Pena-Shaff, J., \& Altman, W. (2015). Student interaction and knowledge construction in case-based learning in Educational Psychology using online discussions: The role of structure. Journal of Interactive Learning Research, 26(3), 307-329. ERIC Number: EJ1070848

Shea, Peter \& Bidjerano, Temi. (2009). Community of inquiry as a theoretical framework to foster "epistemic engagement" and "cognitive presence" in online education. Computers \& Education, 52. 543-553. https://doi.org/10.1016/j.compedu. 2008.10.007.

Sheridan and Kelly, (2010). The indicators of instructor presence that are important to students in online courses. Journal of Online Learning and Teaching, 6 (4). Retrieved from http://jolt.merlot.org/vol6no4/sheridan_1210.htm.

Starko, A. (2013). Creativity on the brink. Educational Leadership, 70(5), 54-56. ERIC Number: EJ1006693.

Yin, R. (2014). Case study research design and methods, (5th ed., ). Thousand Oaks: Sage Publications, Inc.

Submit your manuscript to a SpringerOpen ${ }^{\circ}$ journal and benefit from:

- Convenient online submission

- Rigorous peer review

- Open access: articles freely available online

High visibility within the field

- Retaining the copyright to your article

Submit your next manuscript at $\boldsymbol{s p r i n g e r o p e n . c o m ~}$ 